RESEARCH REPORT

\title{
Mortality in relation to sex in the affluent world
}

\author{
Janefte E Rigby, Danny Dorling
}

J Epidemiol Community Health 2007;61:159-164. doi: 10.1136/jech.2006.047381

See end of article for authors' affiliations

.....................

Correspondence to:

Dr J E Rigby, Department of

Geography, University of

Sheffield, Winter Street,

Sheffield' S10 2TN, UK:

jan.rigby@shef.ac.uk

Accepted 26 May 2006
Background: This paper explores newly available data for 22 countries with reliably recorded mortality data. The past century saw dramatic falls in mortality for both males and females in the most affluent countries of the world. However, these falls are not consistent for both men and women and the inequalities in the male:female mortality ratios are not well understood.

Design: By aggregating mortality at each year of life for the 22 countries for those years for which reliable data were recorded (during the period 1850-1999), distinct patterns emerge.

Results: In the richer countries of the world, the male:female mortality ratio has been widening for all years of age, particularly for those born from 1942 onwards. Specific cohort effects are clearly identifiable.

Conclusion: Analysis of the emergent trends suggests that economic activity, status and position possibly provide a better overall explanatory model than a purely biomedical approach.
Gender differences have been consumed by social change. We are in the midst of an ascent of women matched with an equivalent descent of men. ${ }^{1}$

In the richest fifth of the world, the rate ratio of young men to young women dying per year is $3: 1 .^{2}$ Among these richest of nations, in recent decades, the mortality of younger women has been falling much more quickly than for men..$^{3-6}$ The demographic and social antecedents of this trend, its historical uniqueness and its potential implications for the future population structure of the rich minority of the world are not well understood, and not widely recognised, although many studies have been made of specific aspects of the trends. ${ }^{7-11} \mathrm{~A}$ new international database, ${ }^{12}$ accessible to all researchers, makes the study of 22 countries now possible, ${ }^{\mathrm{i}}$ and the degree of accuracy achieved from amalgamating the data produces new trends for exploration and explanation. The aim of this study was to investigate changes in the male:female mortality ratio over time, and specifically to identify when the trend towards high rates of male/female inequality in mortality began.

\section{METHODS}

The human mortality database project began in 2000, and is jointly maintained by the Department of Demography, UC Berkeley and the Max Planck Institute for Demographic Research, Rostock, Germany. Countries are included if there is a "well found belief that coverage of census and vital registration statistics is relatively high". ${ }^{12}$ Different countries enter the dataset on different dates depending on when their data became reliable: the data have been stringently validated following a strict methods protocol ${ }^{13}$ before being accepted for this database. The datasets contain some caveats in terms of data quality, which informed the time period extracted for this work-that is from 1850 to 1999 . Thus, the geographical area being considered changes in size over time-but at each point in time the area corresponds to those nations of the world that could record reliable mortality data-in effect to the most economically advantaged nations of the world (countries identified as "relatively wealthy"12). Clearly, these findings are unlikely to reflect the conditions in the remaining fourfifths of the world, where so much mortality remains attributable to infectious disease and conflict. ${ }^{14}$
The full dataset used here includes some 1.4 billion people: 702 million women and 695 million men living between 1850 and 1999 in the 22 countries shown in table 1. Of these, almost 1 billion are alive now. People $\geqslant 101$ years of age are not included. Data held include annual live birth counts, annual death counts and population size as on 1 January each year. Hence the data for each country were used to produce counts of deaths by age and sex for each year, and thus to calculate the mortality for each year of life. The male: female mortality ratio was calculated by dividing the male mortality by the corresponding female mortality. The work did not require ethical approval.

It is extremely difficult to visualise changing rates, let alone rate ratios by age and cohort, in our imagination; a map of mortality trends is worth 15000 numbers. Hence, to assist with interpretation, figs 1 and 2 depict Lexis maps ${ }^{\mathrm{ii}}$ of the ratio of male to female mortality by single year of age and year, and of the first derivative of change in that ratio (by age). The $\mathrm{x}$ axis (or easting) represents time, showing the years from 1850 to 2000. There are thus 150 columns of data. The y axis (or northing) represents age, from $<1$ to between 99 and 100 years. There are thus 100 rows of data and 15000 cells in all. Each cell is coloured according to the mortality rates of women and men in each specific year of each particular age. Thus, the top right-hand cell refers to the mortality of people in their 100th year of life living in the calendar year 1999.

The cells in the Lexis map are coloured according to the ratio of female:male mortality. For example, the top right cell in fig 1 is given a shade of orange that corresponds to a ratio between 1.1 and 1.2 on the key to the right of the diagram. This means that for every 1000 men, between $10 \%$ and $20 \%$ more died in the year 2000 before their 100th birthday than did women of the same age group during the same time period. To distinguish between shades of colour, locate the darkest red in the diagram. This refers to mortality ratios of $<1$ (in which case more women died than men). Note that the "ratio surface" on the

'In Spring 2005, Belgium became the 23rd country to be added to the database, which is omitted from the study here. It almost certainly had no effect.

iiThe software used to draw the Lexis maps was Lexis 1.1, written by Kirill Andreev and named after the German demographer Wilhelm Lexis. Available from www.demogr.mpg.de (software at http://www.demogr. mpg.de/books/odense/9/cd/default.htm). 
Table 1 Data forming the "affluent world"

\begin{tabular}{llc}
\hline Country & $\begin{array}{l}\text { Data available at } \\
\text { the time of access }\end{array}$ & $\begin{array}{c}\text { Population in 1999 } \\
\text { (millions) }\end{array}$ \\
\hline Sweden & $1751-2002$ & 8.9 \\
England and Wales & $1841-1998$ & 52.6 (1998) \\
Norway & $1846-2002$ & 4.5 \\
Italy & $1872-2000$ & 57.6 \\
Switzerland & $1876-2002$ & 7.1 \\
Finland & $1878-2002$ & 5.2 \\
France* & $1899-2001$ & 58.5 \\
Spain & $1908-2001$ & 40.3 \\
Canada & $1921-1996$ & 29.8 (1996) \\
Denmark & $1921-2000$ & 5.3 \\
Bulgaria & $1947-1997$ & $8.3(1997)$ \\
Austria & $1948-1999$ & 8.1 \\
Czech Republic & $1948-2001$ & 10.3 \\
Hungary & $1950-1999$ & 10.1 \\
Japan & $1950-1999$ & 125.3 \\
The Netherlands & $1950-1999$ & 15.8 \\
East Germany & $1956-1999$ & 15.3 \\
West Germany & $1956-1999$ & 66.8 \\
Latvia & $1959-1999$ & 2.4 \\
USA & $1959-1999$ & 272.5 \\
Lithuania & $1960-2001$ & 3.5 \\
Russia & $1970-1999$ & 146.3 \\
\hline *Territorial changes during World Wars I and II. & \\
& &
\end{tabular}

Lexis map is quite smooth. Areas of time and age where rates were $<1$ tend to be surrounded by areas where rates were between 1.0 and 1.1, and so on up to the few cells in time and by age where $>3.4$ men died for every woman who died.

The quality of the data allows a single year of age first derivative (a measure of change) to be calculated for the first time. This shows the increase or decrease in any calendar year of mortality ratios comparing one cohort with that aged a year older (fig 2). Here, we are looking at the change in slope by age, so for each cell, we divide its value by the value in the cells below it, relating to people aged 1 year younger. If there is a sudden increase or decrease in the smoothness of the Lexis map's surface, it becomes evident by showing this first derivative. Note that we have smoothed the first derivate surface by taking a 5 -year moving average by age. The average is actually the geometric mean for 2 years younger, 1 year younger, the age group being considered, 1 year older and 2 years older. The geometric mean is calculated as the product of the five ratios (of ratios (of rates)) to the power of a fifth. We only smooth vertically (by age) and calculate the derivative by age, as we would expect some breaks of slope by time as new territories are introduced over time. Therefore, we do not calculate the first derivative over time. We interpret the maps by looking for specific features-for example, diagonal lines of colour will show cohort effects, where vertical chimneys show a situation in a particular year: the World Wars are good illustrations of such period effects. In fig 2, these chimneys appear strongly in blue, but much of the remainder of the diagram before 1950, for the ages between 20 years and 70 years, is green - corresponding to around 1 on the legend, and indicating a relatively stable change as males and females age by 1 year at a time. However, where we see diagonal lines of colour are apparent, for example in dark blue from 1970, the diagonal highlights a cohort of people as they age year by year, and the colour indicates the rate of change: so blue indicates that year on year, the rate of male mortality is worsening compared with that of women. This is explored in more depth in the next section.

\section{RESULTS}

Mortality has fallen rapidly over time in the rich world. In the first half of the 20th century, much of this was attributable to continued public health interventions to supply clean water, sanitation and improved housing quality. In addition, improved healthcare and nutrition were reflected in dramatic falls in maternal and infant mortality. ${ }^{15}$

Before turning to the relative mortality of men to women, trends in each warrant consideration. These are summarised in table 2 below, which shows the total male and female mortality for the data at approximately 10-year time intervals across the 20th century.

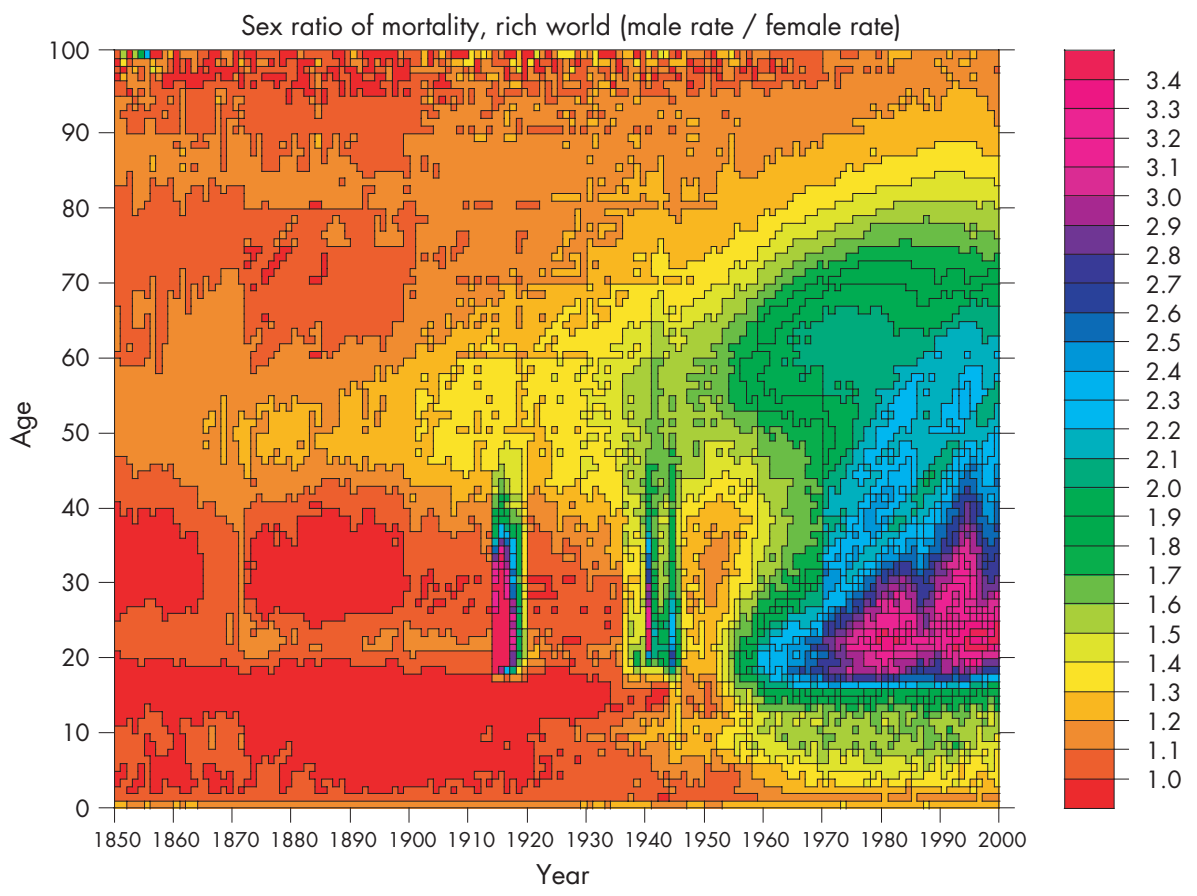

Figure 1 Sex ratio of mortality (male:female) for the richer countries. 


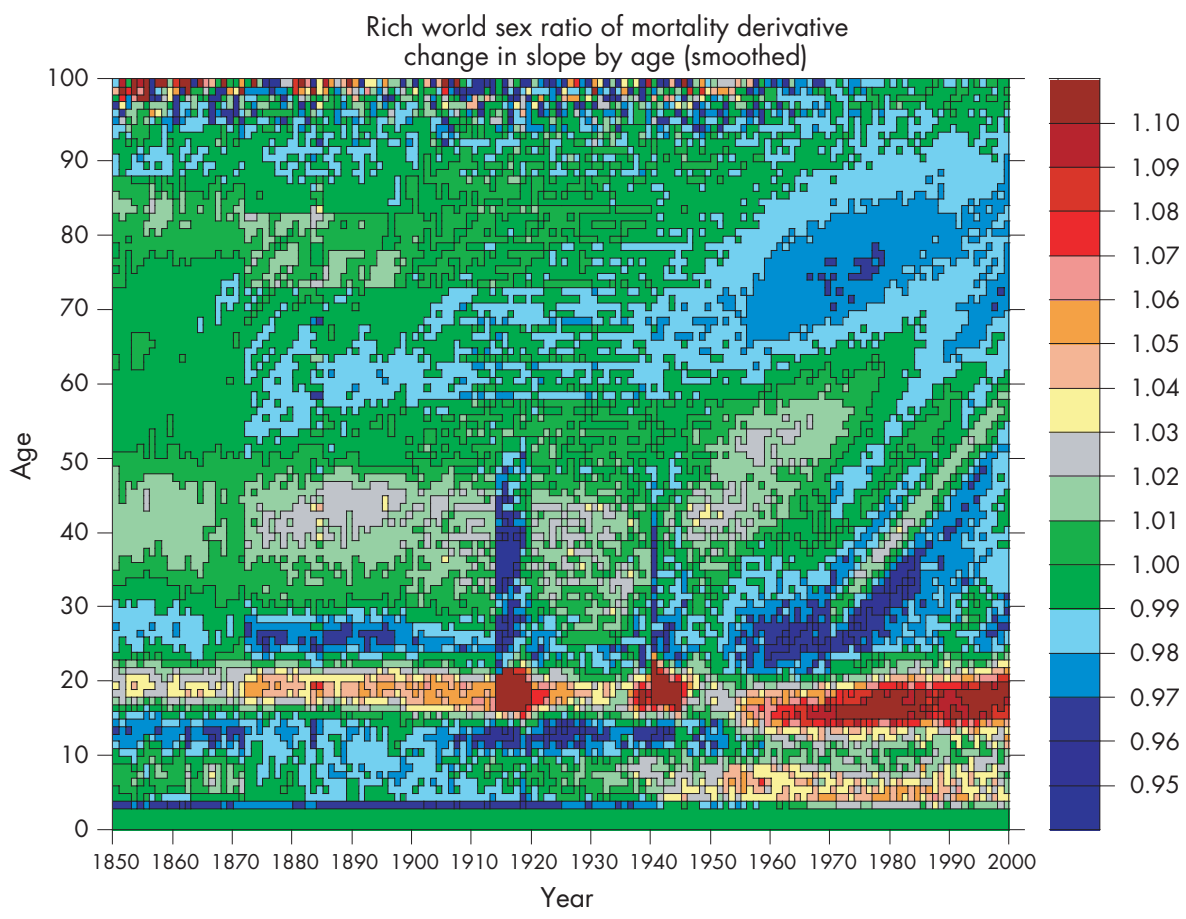

Figure 2 First derivative of sex ratio of mortality, showing change.

From this summarised information, we can see how the rates for males and females fell over the 20th century, but not at the same pace. For specific ages, the figures are particularly noticeable (fig 3).

For 10-year-old girls, rates fell from just under 5 per 1000 in 1850 , to 4 in 1867, halving repeatedly to 2 in 1925, to 1 in 1947, 0.5 in 1955, 0.25 in 1975 and being approximately 0.125 now. For 10-year-old boys, rates were similar in 1850 and the first milestone $(<4 / 1000$ deaths/year) was reached in 1867, but subsequent milestones were attained later than for girls (1926, 1949, 1961 and 1996, respectively); mortality for 10-year-old boys is currently approximately double that for girls of that age.

There has been only one outstanding worldwide single-year period effect in the rich countries between 1850 and 1999. Girls aged 10 years in 1918 experienced a mortality equal to that in women aged 40 years during the years either side of 1918. This shows the historic magnitude of the influenza pandemic of 1918. ${ }^{16}$ For men, the First World War raised mortality in general from 1914 to 1920 , but rates in 1918 were still twice those of earlier and later years for all ages between 1 and 40 years.

Table 2 Overall female and male mortality at 10-year time intervals

\begin{tabular}{llll}
\hline Year & $\begin{array}{l}\text { Female } \\
\text { mortality } \\
/ 1000\end{array}$ & $\begin{array}{l}\text { Male } \\
\text { mortality } \\
/ 1000\end{array}$ & Comment \\
\hline 1910 & 16.76 & 18.28 & \\
1919 & 16.44 & 18.76 & Influenza pandemic \\
1930 & 12.44 & 13.84 & Beginning of the Great Depression \\
1940 & 12.65 & 15.17 & Early World War II in Europe \\
1950 & 9.99 & 11.25 & Beginning of regeneration \\
1960 & 8.63 & 10.59 & Stability and prosperity \\
1970 & 8.56 & 10.33 & Widespread contraception \\
1980 & 8.81 & 10.18 & Periods of recession \\
1990 & 9.01 & 9.83 & Onset of Japanese recession; AIDS \\
\hline
\end{tabular}

The peaks in mortality are more evident for men. These occur at 30 years of age in 1853 at 10.6/1000, falling then and rising again to 10.3 in 1871, falling then and rising through the First World War to peak at 31.6 in 1918, then alternately falling and peaking at the times of the Wall Street Crash in 1929 (5.4), the depression in 1936 (5.2), reaching 9.8 in 1940 during the start of World War II, then falling rapidly to a low of $1.6 / 1000$ in 1967. These rates then rose and fell repeatedly, with peaks coinciding with economic depressions ${ }^{17}$ in 1970 (2.3), 1981 (2.1), 1994 (2.4) and ending with rates of 1.9 in 1999, higher than those in 1958, 40 years earlier. Conversely, mortality for women aged 30 years halved from 1.3/1000 in 1958 to $0.7 / 1000$ by 1999 .

The Lexis maps show trends hinted at by previous studies, ${ }^{4-6}$ but with a degree of accuracy achievable only when the sample size exceeds 1 billion, which has not been achieved previously, and is possible only if this (albeit expanding) area of the globe is considered as a single areal unit of study.

Figure 1 shows the changing ratio of male to female mortality in these rich countries of the world by single year of age each year from 1850 to 1999 . Hence, the greater the scale value, the greater the proportion of men dying than women. Before 1940, at many ages, slightly more women died per 1000 per year than men. The main exceptions were for younger men during the First World War and for those aged 50-60 years from the 1870s onwards, with maximum inequalities being recorded as mortality up to a third higher than for women in particular years at particular ages. For men aged 21 years, mortality was $20 \%$ higher than women of the same ages in $1934,31 \%$ higher in 1936, 60\% higher in 1938 and 300\% higher in 1940. Although falling again after the war, the ratio never fell back to its 1934 level and rose steadily again from 1950 to reach $113 \%$ in $1959,216 \%$ in 1974 and peaking at $251 \%$ in 1995 . By then, for every 100 women dying aged 21 years, some 351 men were dying at that age each year in the rich world.

As fig 1 shows, the recent fortunes of 21 -year-old men were part of a general trend that began around 1950 for men aged 


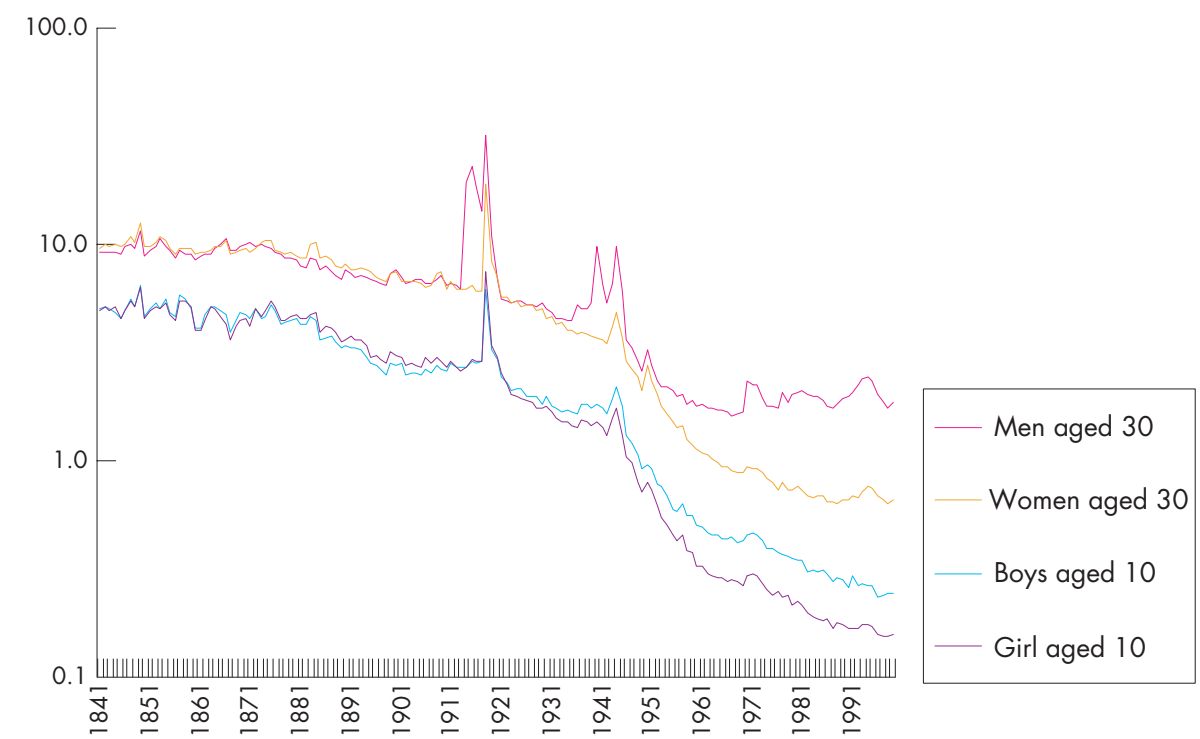

Figure 3 Mortality /1000/year (logarithm scale): affluent countries of the world, selected single years of ages 10 and 30 years, male and female, $1841-$ 2000.

around 20 years, included all those aged $20-30$ years by 1960 , extending to 40 years of age by 1970, 50 years by 1980, 70 years by 1990 and covering the ages of $20-80$ years by 2000 , for whom it became normal to die at almost twice the rate of women per year. Although this triangle has been identified previously, ${ }^{4}$ it has not been mapped in as much detail as here and that detail provides more clues as to its possible origins. At the heart of this triangle, for men in their 20s in particular years in the 1980s and 1990s, rates of mortality three times those of women became normal. This is an unprecedented level of inequality in the richest countries of the world. While deaths attributable to AIDS in younger men might contribute to this phenomenon, the contribution is relatively small, particularly for the youngest ages most affected (early 20s) and in the period in which inequalities became the highest (1990s), before antiretroviral treatment became effective.

Figure 2 shows the first derivative of change in fig 1 by age. Clearly, the increases in the ratios which have occurred over time are cohort-led-that is, from around 1950 onwards diagonal trends appear in the change in rate ratios. The first of these trends is for men aged around 80 years in 2000 who would have entered the labour market in the 1930s; the second for men aged 68 years in 2000 who were 15 years in 1947; the third for men aged 58 years in 2000 (aged 15 years in 1957); the fourth for men aged 37 years in 2000 (entered labour market in late 1970s or early 1980s); the fifth for men aged 24 years in 2000 (entry in early 1990s); and the sixth for men entering the labour market around 2000. Each of these cohorts is of men who had to compete for work more than was normal (as compared with men born slightly earlier or later), both as a product of when they were born and of subsequent economic circumstances. For later cohorts that competition has also been increased as women have entered competing (rather than separate) labour markets in increasing numbers. ${ }^{18}$ Figure 1 also shows how, in terms of changes to the ratios, the worse years of the two world wars are similar regarding effect of social change since 1960.

Figure 4 shows male:female mortality by age for successive 10 -year cohorts from 1850, exploring the trends over time. The lowest line in the figure and the first cohort is of all people born between 1850 and 1859. For this cohort, ratios at all ages were near 1 , and the same proportion of men and women died each year as they aged. For successive cohorts, the flat lines of risk rise slowly and then more rapidly until, for men born in the 1930s, their chances of dying between ages 40 and 65 years were twice those of women born in that decade. This rise in male mortality in the middle age coincides with the rise in smoking (originally more among men). ${ }^{10}$ For men born before the turn of the century-cohorts in the 1880s and 1890s-ratios rise at the age they would have been during the First World War. There are shallow peaks for those born in the 1910s and 1920 s at the ages they would have been most likely to have been fighting in the Second World War.

From the cohorts of those born in 1940s onwards, the peak age of inequality quickly becomes the early 20 s and there is little subsequent rise in inequalities at older ages. By the time the members of the 1970s-born cohort reached their early 20s, male:female mortality inequalities had exceeded 3:1, and both the 1980s-born and 1990s-born cohorts were following similar trajectories. On analysing fig 2, it can be discerned that the trend changed the fastest for those children born in 1942. Men born in this year in the rich world were the first to be twice as likely to die as women, each year, from the age of 18 years onwards.

\section{DISCUSSION}

Manhood tells a social tale as much as one written in nucleic acids. It must, with all that it implies be constructed, and once its foundations are laid, what rises from them has little to do with DNA. ${ }^{19}$

For those born since 1942, by the age of 18 years men have been twice as likely to die per year than women. Their relative chances then exceed this until they reach their 50s, when again they are twice as likely to die per year. Below 20 years and above 50 years of age inequalities between men and women have been stable over the course of more than four decades. Between the ages of 20 and 50 years, subsequent cohorts of men have experienced successively poorer relative mortality as compared with women. At times, male mortality rises in absolute terms for men of these ages, whereas for women it relentlessly falls. What has changed since 1942 to create these new trends? 


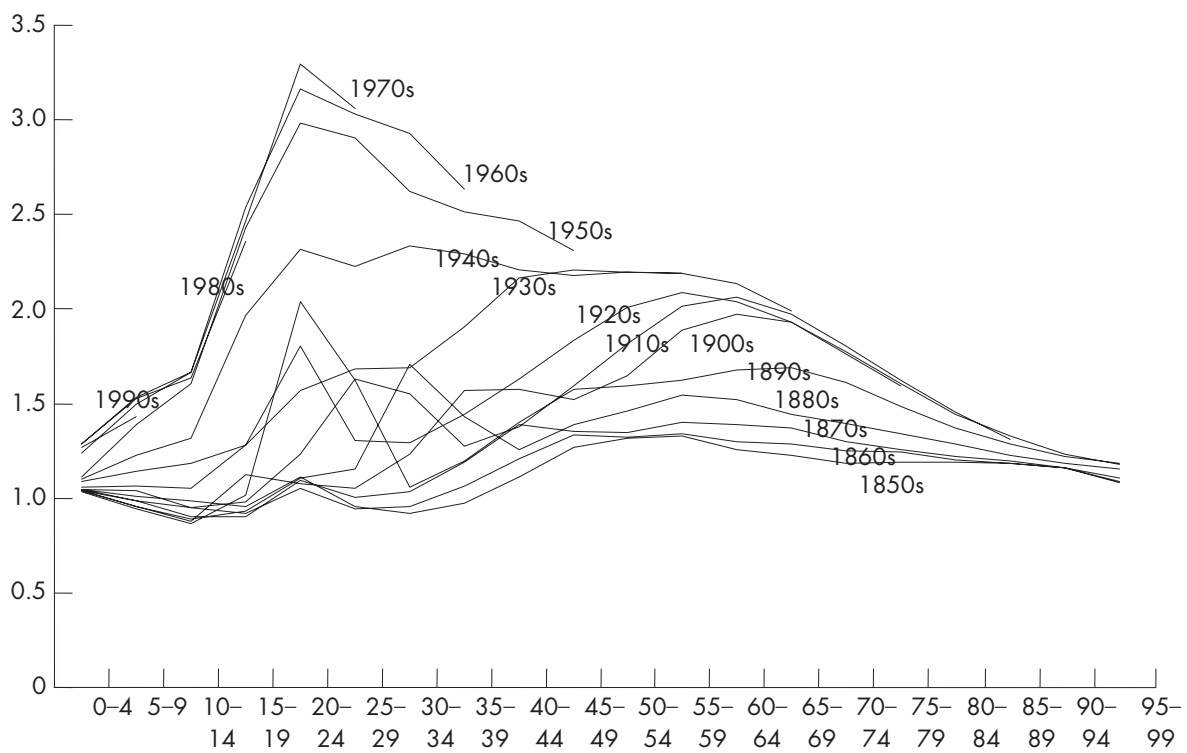

Figure 4 Male/female mortality ratio by age in the rich world by 10-year cohort (1850-1990).

In 1942, the rich world was in turmoil. The United States had joined the war a few weeks before the start of the year. Stalingrad was held, with huge losses, by the Russians, and at El Alemein, the course of the war changed in the autumn of that year. However for those born during the height of this war, it was the social changes that came later that most influenced their lives. When they turned 18 years in 1960, the contraceptive pill was first marketed in the United States, coming a year later to Germany. ${ }^{20}$ Women born in rich countries around 1942 were among the first in the world to have substantial control over both their bodies and social destinies. As Jones succinctly phrases it, the changing social relationships between men and women were what led to the current descent of men. ${ }^{19}$

No single medical, biological or "lifestyle" explanation can account for why young men's mortality is improving so much more slowly than that of young women across all the richer nations of the world. Unlike the early rise in inequalities at older ages, there is no obvious agent such as the introduction of mass-produced cigarette sales being clearly biased towards men, and no small group of causes accounting for the majority of inequality. ${ }^{7}$ The work of Gjonça et al makes a very useful contribution to identifying social and biological factors when comparing England and Wales with France, but does not explore the crucial history of their economic contexts. ${ }^{8}$ Given the history of epidemiology and public health, it is not surprising to find the predominance of biological explanations frequently suggested, ${ }^{45}$ and indeed we may be witnessing the outcomes of some evolutionary processes that are only just emerging. However, any mechanical explanation has to encompass the whole growth in relative inequalities from 10 to 80 years of age from the middle of the past century to the start of this one. No single biological explanation can account for why a 10-year-old boy is half as likely again to die as a girl of that age in any given recent year, likewise for an 80-year-old man compared with an 80-year-old woman. ${ }^{21} 22$ In 1912, their chances were almost equal. Although aspects of high-risk behaviours (reflected in road accidents, suicides and lethal drug misuse statistics) feature in explanations of higher mortality for young male adults, ${ }^{5}$ such explanations are hardly applicable for boys aged 10 years.

Figure 3 shows the mortality separately for males and females, for the single ages of 10 and 30 years. The influenza pandemic, and for males the First and Second World Wars, and post-war economic depressions, are all evident. It is also clear that the male/female rates for 10 -year-olds begin to diverge at the same time as those for 30-year-olds, from the mid-1940s.

The recent collection of reliable, validated historical mortality data from around the world allows both the patterns at large to be studied and individual countries' trajectories to be compared. There may well be clues in the fluctuations to the general trend that point to its origins and likely future. Ratios improved slightly more slowly for women under the rule of Mussolini in Italy and Franco in Spain, for instance. Between the ages of 5 and 14 years, many more girls died in 1918, for all years studied, than did boys. Did fascist regimes perhaps hold back women's emancipation enough to slightly influence relative mortality? Were boys perhaps valued so much more than girls that in times of stark deprivation (during war and pandemic in 1918) more brothers were kept alive than their sisters? The variations between the fortunes of men joining the increasingly global labour market at dates determined by their birth (listed above) provide more clues, through the coincidence of events, of the underlying processes at play. It may just be coincidence that men suffer more biological effects during recessions, benefit from recessive regimes and die less in childhood in one unique year. Alternatively, perhaps all these signs point to the growing importance of social context in terms of sex equality and most importantly, female emancipation in the rich world. ${ }^{23}$

If women's emancipation is the driving force of this global trend, then the prospects for men's future are not good, as in almost all rich countries the economic and social position of women still has a long way to improve to reach that of men. Fourfold and fivefold mortality inequalities are not hard to imagine at particular ages in the near future, especially in particular countries (the ratio already exceeded 3.5 in 1995 for men aged 21 years). Just as the causes of these inequalities are not medical, nor will the solutions be.

Clearly, this study is limited to the findings from the data available - that is, those countries that had the infrastructure to supply the human mortality database with population and mortality data which met its stringent requirements. All available countries were included at the time this paper was written. There are other, affluent countries that are not in the database, but their populations are unlikely to be large enough to affect the trends 


\section{What is already known}

- It is already widely known that in rich nations, mortality in young males is now several times higher than that in females rates and that this relative differences has widened as absolute rates have fallen rapidly for both women and most groups of men.

- However, almost all studies focus on single -nation states or compare a small number of nations. Few studies group nation states to dramatically increase the sample size and allow more subtle trends to be identified with what is already known. Those subtle trends may produce clues as to why relative inequalities are increasing as they are.

\section{What this paper adds}

This study adds the most detailed description of this trend to date in terms of volumes of data involved and hence the clarity of the patterns that result. This allows the second derivative of the trend to be taken - the trend in the trend-and key dates to be identified when it seems that increases in the relative ratios of male to female mortality coincide with cohorts entering world labour markets during more economically depressed times. This study suggests that international socioeconomic factors need to be carefully studied to better understand the recent history of mortality among the most affluent billion people of the world.

discussed. We also acknowledge that the historical events incorporated in the discussion are, although persuasive, clearly subjective and influenced by our UK perspective.

In the richer nations of the world, the lives and social roles of young men and women only vaguely resemble those of their grandparents. If the same order of change were to occur in the next two generations, then perhaps the relative descent of men could decelerate. As yet there is no strong evidence for that. It can, however, be seen that the step changes in fig l start to shift direction in the upper age ranges (over 70 years) from about 1990; this convergence might reflect the "rounding off" of the middle-aged bubble. This study suggests that international socioeconomic factors need to be carefully studied to better understand the recent history of mortality among the most affluent billion people of the world.

\section{ACKNOWLEDGEMENTS}

We thank Charles Pattie and Eilidh Garrett, and four reviewers, for their helpful comments on an earlier version of this manuscript.

\section{Authors' affiliations}

J E Rigby, D Dorling, Department of Geography, University of Sheffield, Sheffield, UK

Competing interests: None.

\section{REFERENCES}

1 Jones S. Y: The descent of men. London: Abacus, 2003:260.

2 World Health Organisation. World health report 2004. Geneva: World Health Organisation, 2004.

3 Vaupel JW, Carey JR, Christensen K, et al. Biodemographic trajectories of longevity. Science 1998;280:855-60.

4 Waldron I. Recent trends in sex mortality ratios for adults in developed countries. Soc Sci Med 1993;36:451-62.

5 Kruger DJ, Nesse RM. Sexual selection and the male:female mortality ratio. Evol Psychol 2004;2:66-85.

6 Wingard DL. The sex differential in morbidity, mortality and lifestyle. Annu Rev Public Health 1984;5:433-58.

7 Conti S, Farchi G, Masocco M, et al. Gender differentials in life expectancy in Italy. Eur J Epidemiol 2003;18:107-12.

8 Gjonça A, Tomassini C, Toson B, et al. Sex differences in mortality, a comparison of the United Kingdom and other developed countries. Health Stat $Q$ 2005;26:6-16

9 Guralnik JM, Balfour JL, Volpato S. The ratio of older women to men: historical perspectives and cross-national comparisons. Aging Clin Exp Res 2000;12:65-76.

10 Pampel FC. Cigarette use and the narrowing sex differential in mortality. Popul Dev Rev 2002;28:77-104

11 Verbrugge LM, Wingard DL. Sex differentials in health and mortality. Women Health 1987; 12:103-45.

12 Human Mortality Database. University of California, Berkeley (USA), and Max Planck Institute for Demographic Research (Germany). www.mortality.org or www.humanmortality.de (data downloaded on 20 Nov 2004; accessed 5 Nov 2006).

13 Wilmoth JR, Andreev K, Jdanov D, et al. Methods protocol for the human mortality database. www.mortality.org (accessed 5 Nov 2006).

14 World Health Organisation Mortality Database. www.ciesin.org/IC/who/ MortalityDatabase.html (accessed 5 Nov 2006).

15 Loudon I. Maternal and infant mortality 1900-1960. Soc Hist Med $1991 ; 4: 29-73$.

16 Cliff AD, Hagget P, Ord JK. Spatial aspects of influenza epidemics. London: Pion, 1986.

17 Webber MJ, Rigby DL. The golden age illusion: rethinking postwar capitalism. New York: Guilford Press, 1996.

18 Rogot E, Sorlie PD, Johnson NJ. Life expectancy by employment status, income and education in the National Longitudinal Mortality Study. Public Health Rep 1992;107:457-61

19 Jones S. Y: The descent of men. London: Abacus, 2003:239-40.

20 Foster P. Women and the health care industry. Buckingham: Open University Press, 1995.

21 Owens IPF. Sex differences in mortality rate. Science 2002;297:2008-9.

22 Moore SL, Wilson K. Parasites as a viability cost of sexual selection in natural populations of mammals. Science 2002;297:2015-18.

23 Sen A. More than 100 million women are missing. NY Rev Books 1990;37:61-6.

\section{bmjupdates +}

bmjupdates+ is a unique and free alerting service, designed to keep you up to date with the medical literature that is truly important to your practice.

bmjupdates+ will alert you to important new research and will provide you with the best new evidence concerning important advances in health care, tailored to your medical interests and time demands.

Where does the information come from?

bmjupdates+ applies an expert critical appraisal filter to over 100 top medical journals

A panel of over 2000 physicians find the few 'must read' studies for each area of clinical interest

Sign up to receive your tailored email alerts, searching access and more...

www.bmjupdates.com 